Published in "Development in Practice 29(3): 336-348, 2019"

which should be cited to refer to this work.

\title{
Climate change research in bilateral development programmes: experiences from India and Peru
}

Veruska Muccione, Boris Orlowsky, Simon K. Allen, Christian Huggel, Nadine Salzmann, Nilton Montoya, Surjeet Singh Randhawa and Markus Stoffel

ABSTRACT

This article reflects on the merits and shortfalls of bilateral research programmes aimed at strengthening climate change research capabilities, using the experience from two programmes, the PACC and IHCAP in Peru and India, respectively. The study highlights key aspects of these types of bilateral programmes, namely: capacity; performance, salary and appreciation; funding; bureaucracy and hierarchy; publishing; and data sharing. Furthermore, it emerged that these programmes would benefit from a more extensive consolidation phase of the research activities and partnership rather than rapidly transferring into out- and up-scaling phases.

\section{KEYWORDS}

Environment (built and natural) - Climate change; Aid - Capacity development; Latin America and the Caribbean; South Asia

\section{Introduction}

Academic research has substantially contributed in drawing attention to the challenges of climate change and related impacts on different scales, and to create a knowledge base on options to adapt and mitigate adverse effects of climate change (Salzmann et al. 2016). However, climate change research contributions from developing countries remain sparse, as reflected, for example, by a significant North-South imbalance in the authorship of Intergovernmental Panel on Climate Change (IPCC) assessment reports (Corbera et al. 2015). The persistent North-South divide in research is observable in terms of full-time equivalent number of researchers, expenditure in research and development, and amount of scientific and technical outputs (World Bank 2017). In relation to climate change, a number of studies have outlined how scientific knowledge on climate change is commonly led by scientists and research institutions in the North (Hulme and Mahony 2010; Pasgaard and Strange 2013; Corbera et al. 2015), with a corresponding imbalance of knowledge about regional and local aspects of the climate systems of North and South. Recent publications consequently show how those countries in greatest need of assistance to cope with climate change (least developed countries or small islands developing states) are also those with least documented knowledge and baseline data (Pasgaard and Strange 2013; Salzmann et al. 2014) on climate-related impacts (Huggel et al. 2016; Muccione et al. 2017). The lack of science-based knowledge on climate change can furthermore weaken the positions of developing countries in international negotiations (Hewitson 2015). The extent of the North-South research divide in climate change has been attributed to the difficult conditions of doing research in Southern countries, such as low expenditures in education, research and development, poor governance, instability and reduced press freedom (Pasgaard and Strange 2013).

The international community has started to address the lack of adequate research and training in general, and on climate change in particular, at the institutional and academic level in developing

CONTACT Veruska Muccione veruska.muccione@geo.uzh.ch 
countries (Blicharska et al. 2017). However, progress has so far been rather slow (Blicharska et al. 2017).

This paper attempts to shed light on the underlying factors that hinder or favour the success of bilateral donor programmes aimed at fostering capacity in climate change research and training at the academic level. The research draws upon experiences gained from two programmes cofinanced by the Swiss Agency for Development and Cooperation (SDC) under its "Global Programme Climate Change and Environment" (GPCCE), namely the "Programme for Climate Change Adaptation" (PACC) in the Peruvian Andes and the "Indian Himalayas Climate Adaptation Programme" (IHCAP) in India. Both programmes supported various forms of knowledge generation and dissemination and created learning opportunities in climate change for Southern partners.

In particular, we address the following research questions: how is the institutional and policy context (not) conductive to research excellence in climate change? What are the main constraints and challenges for undertaking scientific research on climate change in developing countries? What should be done to deal with challenges and capitalise on success stories? These questions are addressed by combining evidence from project reports, a student survey (in the case of PACC only), and official policy documents.

The PACC programme aimed at strengthening fundamental capacities in different research areas relevant to climate change - from climate change impacts on hydrology and glaciers to perceptions on climate change and its relation to other factors by the local population, whereas IHCAP aimed to enhance and connect the knowledge and capacities of research institutions, communities, and decision-makers. Both projects included joint research collaborations as well as capacity building activities (Orlowsky et al. 2016; IHCAP 2016).

Before reflecting on key outcomes, experiences and lessons learnt from the two bilateral programmes, we begin by contextualising the institutional landscapes in Peru and India, in terms of the general conditions for undertaking research and more specifically, in relation to the climate change research agendas in both countries.

\section{Research landscapes in Peru and India}

Over the past 30 years, Peru has faced a profound university crisis, which eventually led to the new university law, Law $n^{\circ} 30220$, aimed at regulating the higher education through a number of reforms (Lavalle and Luis De Nicolas 2017). Since the new university law was approved in 2014, a number of measures have been undertaken to ensure availability of qualified teachers, designated research activities, and managerial structures for quality assurance and transparency (Lavalle and Luis De Nicolas 2017). However, a number of bottlenecks remain partially unresolved. The salary of academic staff is rather low to pay for living expenses and often professors engage in better-paid consultancy positions, leaving little or no time for research. The low financial incentives together with a persistent lack of capacities in basic scientific and IT skills and often insufficient knowledge of English language, prevent the necessary embedment of Peruvian universities in international science collaboration (Concytec 2014). In line with the university reform, the Peruvian Organism for Science and Innovation "Concytec" has designed a number of attractive funding instruments and conditions to improve the quality of the training programmes, increase incentives to retain talents, promote the participation of Peruvian scientists in international programmes, and make research careers more attractive. Yet, the GDP share of funding for research and development remains considerably low in the country, about $0.1 \%$ of its GDP (World Bank 2017).

In India, the broader institutional landscape for tertiary education and scientific research is diverse and characterised by severe heterogeneity in funding and quality (Joseph and Robinson 2014; Padma 2015). There are some 700 universities, ranging from elite institutions funded by the central government, to state-funded universities, and private institutions. In addition, research is conducted and facilitated by state government authorities. Overall funding of research remains at less than $1 \%$ of GDP, despite repeated government pledges to increase investment in research and development. 
To better place the funding for research of both India and Peru in the international landscape, Figure 1 shows the expenditure of India and Peru as percentages of their GDP, together with that of Switzerland (the donor country for the two projects), and the UK and USA (where universities routinely achieve the top-level rankings).

\section{Climate agendas in Peru and India}

Climate change and its negative impacts are recognised as an important topic for the scientific agenda of India and Peru. Therefore, both countries have taken institutional steps to strengthen their scientific understanding of climate change and its threats. The "Agenda de Investigación Científica en Cambio Climático" (National Climate Change Strategy and the National Strategic Plan for Science and Technology) is the main mechanism in Peru to guide the scientific agenda on climate change of regional governments and research institutions. An important aspect in the strategy is a call to strengthen human and institutional scientific capacities, and increase the number of professionals and scientists working in various disciplines pertinent to climate change.

Recognising the significant threat of climate change to sustainable development in India, the Government of India launched the National Action Plan on Climate Change (NAPCC) in 2008. NAPCC seeks to promote understanding of climate change, adaptation, mitigation, energy efficiency, and natural resource conservation while pursuing overall economic growth. NAPCC comprises of eight separate missions, of which two are highly relevant in the context of climate change research and sustainable development across the Himalayan region - the National Mission for Sustaining the Himalayan Ecosystem (NMSHE), and National Mission on Strategic Knowledge for Climate Change (NMSKCC). Both missions are under the implementation and coordination of the Department of Science and Technology.

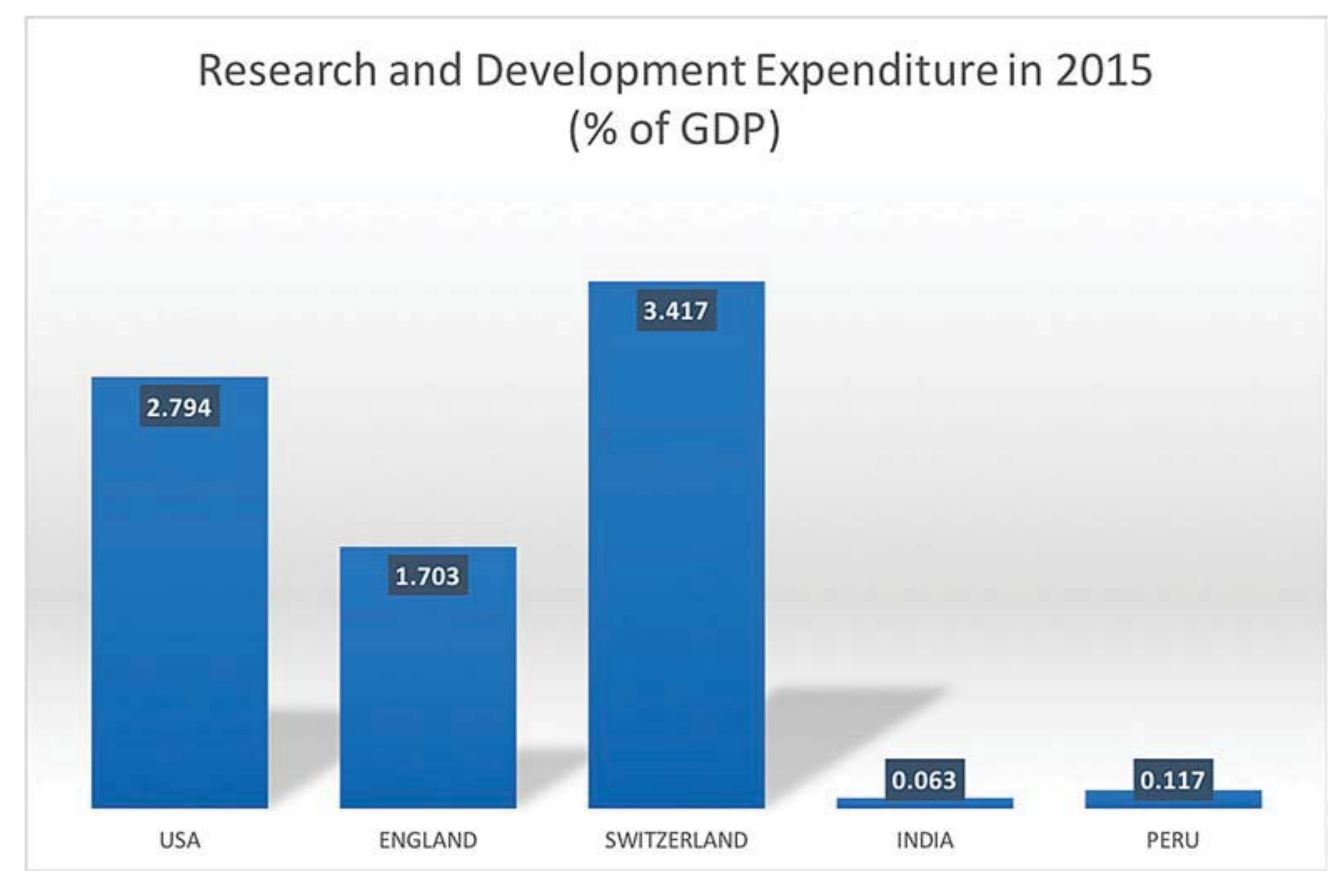

Figure 1. Expenditure as percentage of GDP. Notes: Research and development expenditure as percentage of GDP in 2015 for India and Peru as compared to the donor country (Switzerland) as well as UK and USA. Data for India, Peru, USA, and UK are the World Development Indicators obtained from the Institute for Statistics of the World Bank \& United Nations Educational, Scientific, and Cultural Organization (UNESCO). Data for Switzerland are from the Research and Development Statistics (RDS) of the OECD. 


\section{Case study: experiences from PACC (Peru) and IHCAP (India)}

\section{Research and training in PACC}

The PACC programme emerged as a response to the growing realisation of the impacts of variations in temperatures and precipitation on the country's ecosystems, agriculture, food security, and livelihoods. PACC had three levels of interventions, from the local to the regional and national level. Several capacity building activities were initiated during the lifetime of PACC, with the main objective of creating a knowledge base on research methods and equipping participants with sufficient knowledge to engage in topics related to climate change. Such topics included climate change impacts on glaciers and water cycles, as well as perceptions of change by the local population. Capacity building activities ranged from short courses and development of curricula, to research and study visits to Swiss universities. These initiatives helped create an important scientific knowledge base for the regions involved in PACC and laid the foundations for undertaking research projects focused on adaptation planning and action.

Towards the end of the programme, an ex-post evaluation of the capacity building activities was undertaken. The results showed that the participants rated transferable skill courses (e.g. research methods, scientific writing, technical research tools) more relevant than courses related to scientific topics (e.g. glaciology, hydrological modelling or quality of climate data). The evaluation also confirmed that the English language represented a challenge for the majority of participants. Overall, the capacity building experience was rated as highly important, in particular for providing basic scientific skills and for opportunities to spend time at Swiss universities. Research permanence in the donor country emerged as a very positive experience in the overall capacity building.

As part of the PACC second phase, three research projects at two universities were initiated to foster the transition from scientific studies to adaptation actions. The projects were to be financed by the CANON fund. CANON is the share of the profits from extractive industries in Peru that is devoted to promote public services, including research at public universities. Available funds from CANON are very substantial (> US\$100 million per year) but the spending of these funds is limited by non-ideal regulations (e.g. funds cannot be used to pay salaries of researchers). The progress of the three projects cover a wide range of experiences, from complete shutdown and slow progression to very productive, providing ideal examples to explore the enabling and hindering factors for research project success within public Peruvian universities in the context of climate change.

The first project was initiated by the UNAMBA (Universidad Nacional Micaela Bastidas de Apurimac) to investigate the influence of climate change on a major river basin, responding to increased impacts from landslides and altered hydrological resources and a complex interplay between climate, environment, and land use. At UNAMBA, this project was the first ever submitted to CANON for funding and required setting up the necessary regulations. The already complicated process was additionally delayed by strikes and institutional changes at the university as a result of the new university law. Due to these overly difficult institutional conditions, the project was not pursued any further after submission.

The second project was conceived in parallel to the ongoing implementation activities of PACC, which supported the establishment and restoration of ancient water harvesting structures to alleviate water shortages during the dry season. The project aimed at establishing a sound water balance for selected structures in the Huacrahuacho basin, Cusco region, in order to evaluate their efficiency and support their management. The hosting university was the Universidad Nacional de San Antonio Abad de Cusco (UNSAAC). Despite the UNSAAC already having CANON regulations set up, it took two years for the project proposal to be approved, partly due to inefficient handling of the proposal by the administration, but also due to an insufficient management of the process by the project leaders. PACC came to an end precisely at the time when funding for this project had been released.

The third project addresses the frequent gap around social science investigation in climate change adaptation, exploring perceptions of risks associated with shrinking glaciers and climate change 
among the rural population of the Chicón basin, Sacred Valley, Cusco. The project was initiated at the UNSAAC, thus under very similar administrative conditions to the second project. However, the project was approved within less than one year and became fully operational directly afterwards. The project team and main investigator worked with a high commitment from the beginning, actively engaging with the (at times slow) administration of the university. To overcome limitations in terms of basic scientific and more specific research skills, the project team pro-actively sought support from the Swiss partners. Whereas this process of capacity building "on-the-job" is still ongoing, the steep learning curve allowed for continuous advancement of the project.

It is worth mentioning that beyond the success or failure stories, PACC served as a first-of-its-kind experience for the UNSAAC to become more involved in climate change and water research. Directly following expeditions undertaken during the PACC first phase, two CANON-funded research projects had been formulated and approved within a short time, involving cooperation with international research institutions (including institutions from the USA).

The scientific outputs from PACC have been considerable, producing a number of scientific articles (see Orlowsky et al. 2016). These articles aim at providing a scientific baseline to further the understanding of the regional context and its vulnerability. They are the outcome of collaborations between Peruvian and Swiss researchers, although in only very few cases is the first author a Peruvian researcher.

To strengthen the capacities in international publishing, the Swiss partners supported the UNSAAC to create a new scientific journal titled "Climate Changes in the Tropical Andes", which publishes both in Spanish and English. Despite some challenges, the journal gives an opportunity to local researchers to train their scientific writing skills and increase their visibility. Several articles from the three research projects were published in this journal, first-authored by Peruvian researchers and written in Spanish. An overview of the scientific output from the project is provided in Figure 2. The publications are shown following the project timeline which focused first on capacity building, second on research. and third on synthesis.

\section{Research and training in IHCAP}

IHCAP fits into the Indian research landscape as a key knowledge and technical partner, supporting and facilitating the implementation of the NMSHE, and responding to some of the challenges

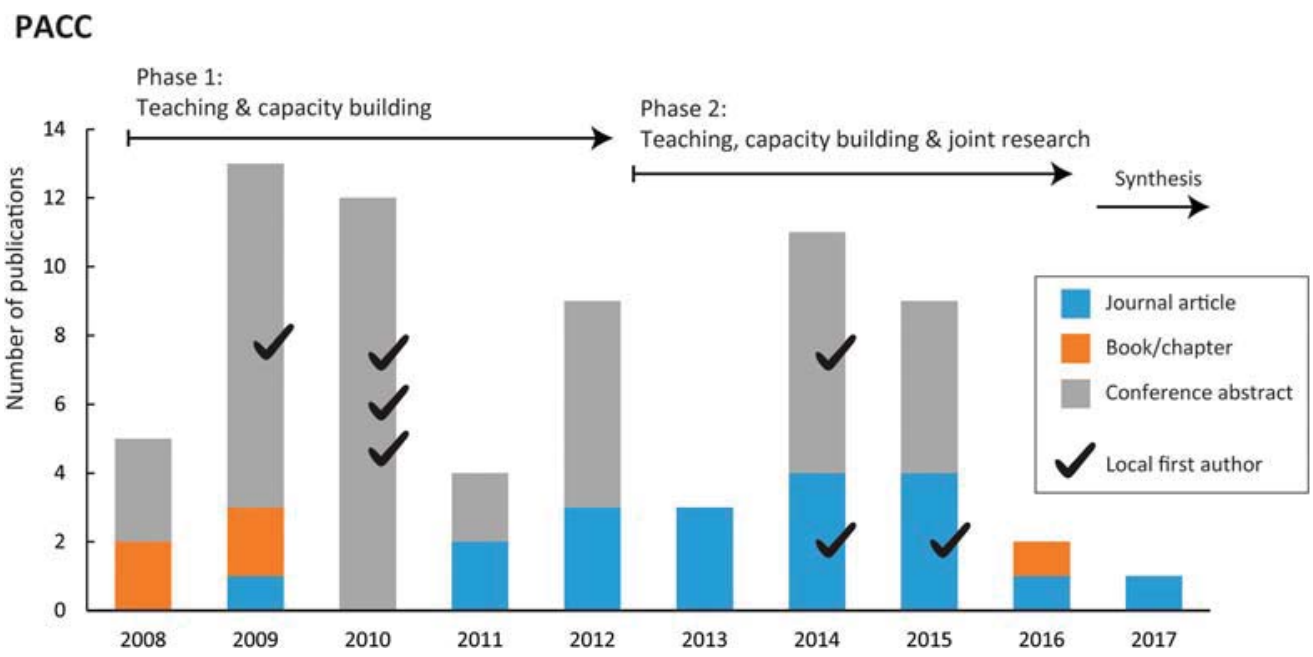

Figure 2. PACC publications. Notes: Number of publications (scientific publications, book/chapter, conference abstracts) produced during the PACC lifetime. Publications having a local first author are also indicated. 
identified in the Himachal Pradesh State Action Plans for Climate Change (SAPCCs), namely the development of a comprehensive catalogue of climate change research, with an emphasis on publishing key state-sponsored climate research. In this regard, IHCAP focused efforts particularly in the fields of glaciology, hydrological impacts and related hazards, which are seen as traditional strengths of the Swiss research community. Related joint research and publications under IHCAP were seen as a vehicle for enhancing local institutional capacities. In parallel to the joint research activities, Indian and Swiss scientists were engaged in a graduate-level training programme in Himalayan Glaciology, hosted at Jawaharlal Nehru University, Delhi, aiming to build capacities with the next generation of young Indian scientists. In Himachal Pradesh, the state Centre on Climate Change (HPCCC - under the auspices of the State Council for Science Technology \& Environment) was the primary partner for several of the joint research activities concerning the cryosphere and climate-related hazards. Meanwhile, research activities relating to climate impacts on ecosystems, agriculture, and tourism were undertaken in collaboration with state universities and other research institutes. The research activities and resulting publications primarily focused on the district of Kullu (central district located in Himachal Pradesh), selected as the pilot site for the first phase of the programme.

The joint research activities of IHCAP only began in May 2014, about midway through the first phase of the programme, while in the meantime efforts focused on the multi-level training programme in Himalayan Glaciology. Before the joint research activities could commence, contract negotiations between the IHCAP Project Management Unit and various Indian partner institutions (universities, research institutes, and state authorities) needed considerable time, with administrative procedures further complicated by Indian elections in late 2013. A first face-to-face meeting of all project partners followed in September 2014 at the official kick-off meeting for the Kullu pilot studies, leaving only 12 months within which to undertake and synthesise wide-ranging climate impacts studies in Kullu district.

Recognising the importance of high-quality baseline data, fundamental analyses of observed or projected changes in key atmospheric and cryospheric variables were undertaken, serving as a basis for studies which addressed one or more of the underlying risk components of hazard, vulnerability, and exposure. For example, studies looked into community perceptions of vulnerability in agricultural or ecosystem-service sectors using participatory surveys, while other studies focused on the physical assessment of climate-related hazards such as floods and landslides. One study integrated across all components to provide a complete risk assessment for glacial lake outburst flooding (Allen, Linsbauer, et al. 2016). In total, 15 collaborative studies were initiated in Kullu district, with results compiled in separate project reports, before key messages were integrated into a final synthesis report (IHCAP 2016).

Several peer-reviewed journal articles have emerged directly from the joint research activities in Kullu (Figure 3), while many more scientific articles and book chapters emerged under the wider framework of IHCAP, primarily led by Swiss authors. Notably, Indian-led international publications emerged later and only after official engagement of Swiss scientists in the programme had ended, hinting at the longer timescales needed to truly generate joint research output and publications. The published studies were mostly focused on climate-related hazards (floods, landslides, avalanches and lake outbursts), but also new baseline studies on key components of the cryosphere. This research did not extend to considering future climate scenarios, but rather emphasised the very real climate-related challenges facing the region today.

Joint research projects by definition include a strong element of capacity building, as the exchange of knowledge and ideas between the partners is an inherent part of the process, a type of learning or exchange on the job. Under IHCAP this was viewed very much as a mutual exchange, as both sides brought a high level of expertise and experience to the table. However, given the narrow time constraints, this aspect was not optimised to the extent that may have been otherwise possible, as opportunities to jointly discuss and share experiences were limited, particularly face-toface, and following the final delivery of results, there were no mechanisms in place to support longterm exchange or ongoing collaboration. 


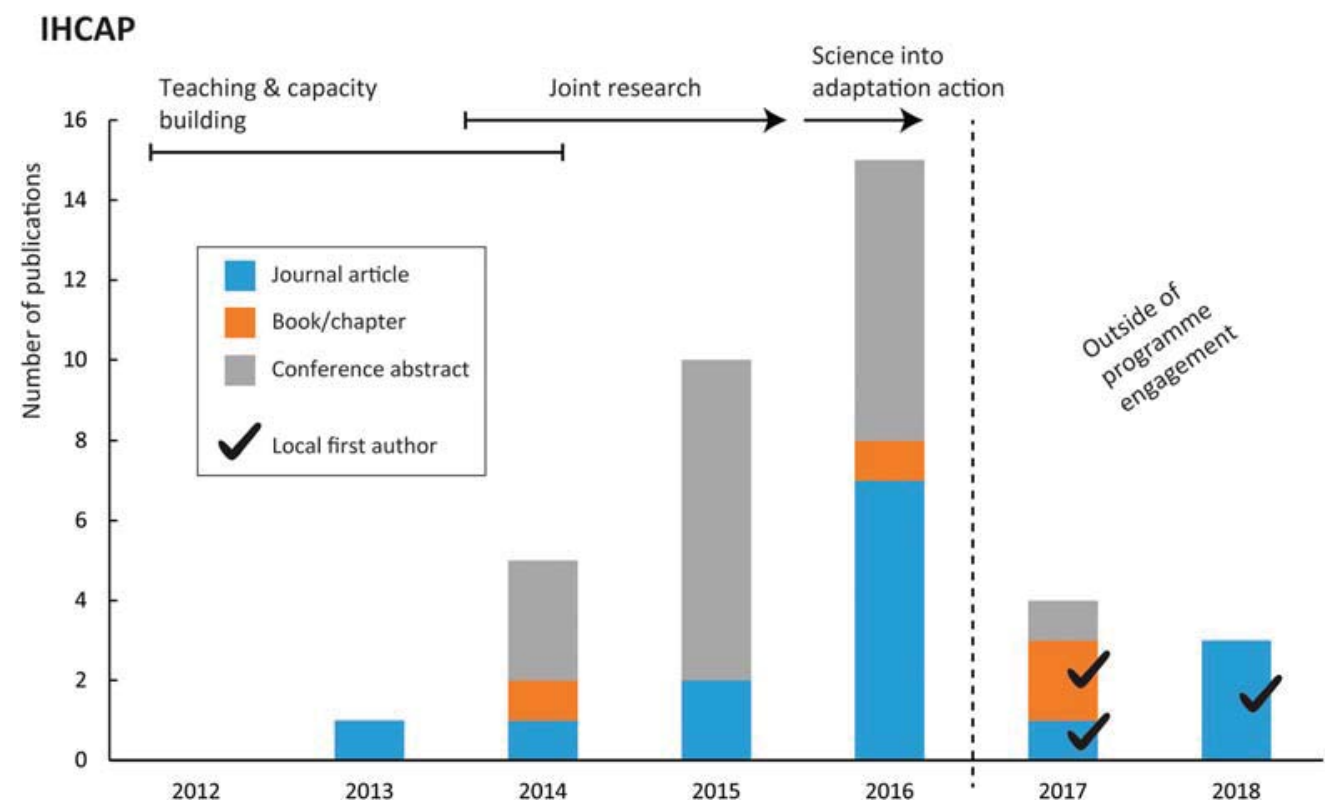

Figure 3. IHCAP publications. Notes: Number of publications (scientific publications, book/chapter, conference abstracts) produced during the IHCAP lifetime and beyond. Publications having a local first author are also indicated.

Where new methodological techniques or topics were introduced through IHCAP, the capacity building received greater emphasis. For example, the distribution of permafrost (permanently frozen ground) had previously not been studied in the Indian Himalayan Region, but under IHCAP, modelling approaches and concepts based on long-standing research in the Swiss Alps were implemented in Kullu district (Allen, Fiddes, et al. 2016). Similarly, Ballesteros Cánovas et al. (2017) introduced innovative dendrogeomorphic techniques to reconstruct historical flood characteristics in data-poor catchments of Kullu district. To sensitise local scientists to these fields of research, several exchange visits took place (hosted in both Switzerland and India) and conferences/seminars were attended. These face-to-face exchanges proved to be of greatest importance for the progress of the programme. Despite the majority of meetings under IHCAP taking place in India, the visit of Indian scientists to Switzerland in June of 2015 proved most beneficial and was considered a major success by all participants.

\section{Key challenges of bilateral North-South collaborations in climate research}

Figure 4 provides an insight into the selected capacity building activities from IHCAP and PACC and of the commitment and exchange of southern and Swiss partners involved in the activities. The collaborative research and capacity building experiences from PACC and IHCAP have provided invaluable material that allows us to reflect upon the status of research on climate change in India and Peru, and more importantly on the general conditions conductive to research excellence and bilateral exchange in those countries. Based on the institutional analysis, India is institutionally far more advanced in climate change research and policy than Peru, both at the national and state level. The NAPCC and the SAPCC are elaborated plans that include a number of detailed missions and clear calls for strengthening climate change research and sustainable development.

Below, we elaborate on key aspects of the scientific research divide and collaborations attempting to overcome it, using the experiences from PACC and IHCAP. These key aspects are capacity, performance, salary and appreciation, funding, bureaucracy and hierarchy, publishing, data sharing. 

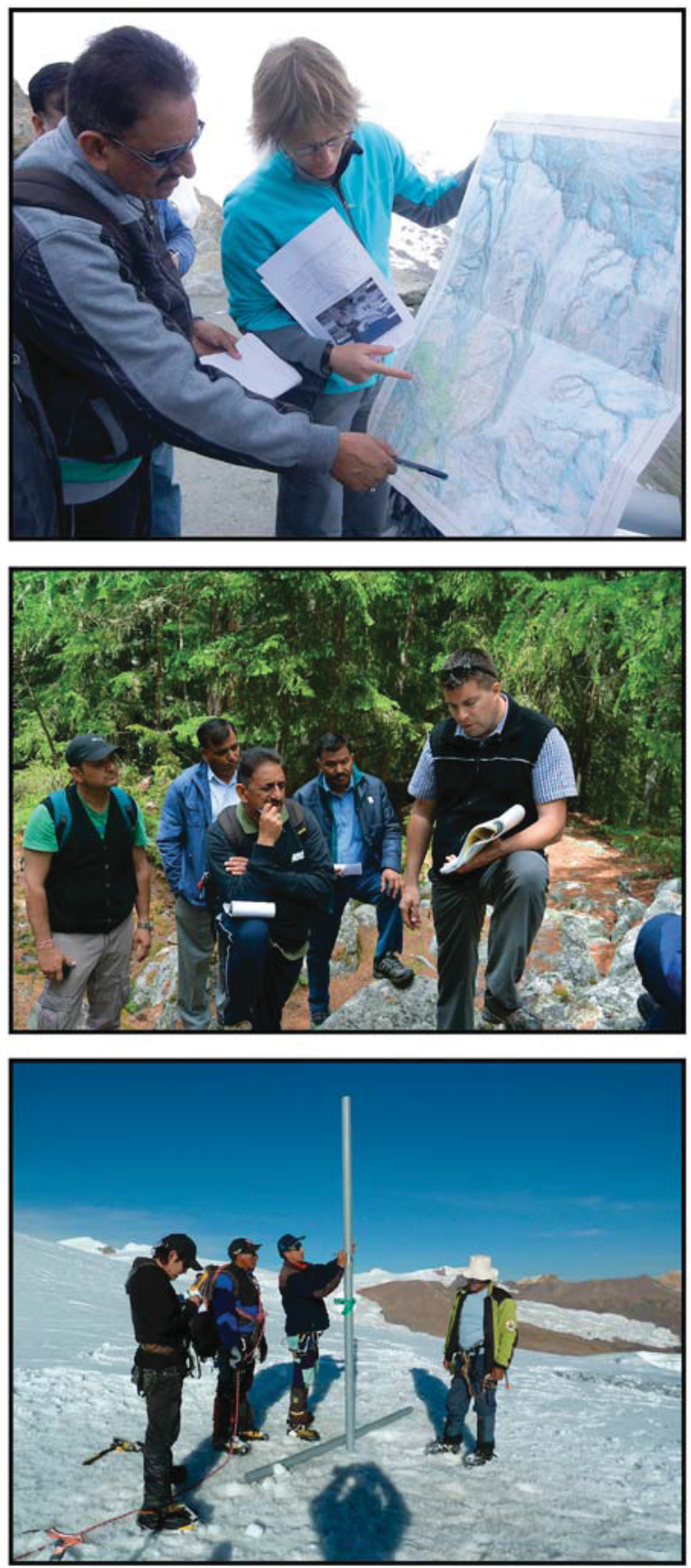

Figure 4. Indian and Swiss scientists discuss impacts of climate change in the Swiss Alps during an exchange visit under IHCAP hosted in Switzerland, June 2015 (top and middle). Peruvian scientists undertake glacier monitoring under PACC, July 2010 (bottom). Notes: Images from B. Saklani and C. Huggel.

Capacity. The two case studies show that the entry points for capacity building interventions differ between India and Peru. In India, there exists a well-established research culture and institutional setting, albeit marred by uneven distribution of resources and bureaucratic complexities. In India therefore, the joint research programme aimed at addressing some specific knowledge gaps 
related to climate change impacts in mountain environments, for which the Swiss partners have a renown and extensive knowledge. In Peru on the other hand, it was more the case of creating such knowledge from scratch and often creating fundamental research skills (i.e. research methods, scientific writing, data acquisition, and analysis) before tackling content-related gaps.

Performance, salary, and appreciation. Research conditions at public regional universities (salary, time allocation, recognition) are hardly a motivational driver for research commitments and increasing research outputs in Peru. As a consequence, research is not competitive enough by international standards and there is a lack of basic understanding and skills in good scientific practice. By contrast, in India, the top institutions have proven capable of producing world-class research of the highest standard, although resources for teaching and research are lacking in many of the smaller statefunded universities. Thus in both India and Peru, improvements on several fronts need to be made in order for academic research to become an attractive career option for promising young graduates (Varshney 2015).

Funding. Figure 1 shows the large funding shortfall in Peru and India, relative to more developed countries. Funding is in principle sufficient in Peru through the proceedings of the CANON fund, which directs significant amounts of the surpluses of the extractive industries to public universities and research institutions. Concytec has furthermore allocated a considerable budget for the advancement of research. However, funding schemes such as CANON do not address research shortfalls adequately, for example by not funding salaries, and hence not creating enough incentives for research. As a result, research in Peru remains poorly resourced, with research expenditures only $0.12 \%$ of the country's GDP. In India, the government funding for research currently ranks below that of other rapidly emerging economies such as China, Russia, and Brazil, and this funding is largely consumed by the leading institutions, leading to a lack of basic infrastructure and resources in other institutions (Joseph and Robinson 2014). However, in the field of climate change impacts research, which have been prioritised under NAPCC and the SAPCC, and well supported through bilateral research programmes such as IHCAP, funding is not, or should not, be a core limitation.

Bureaucracy and hierarchy. Many commentators have spoken of the stifling bureaucracy impeding scientific excellence in India (Majumder 2015), and experiences under IHCAP further support these views, with delays preceding the joint research activities in Kullu. A key problem in the context of bilateral research in India is that any authorisation to engage in project work or even to contribute to a research proposal typically requires multiple levels of authorisation from higher levels of the institutional hierarchy. Hence, there is a reluctance to move forward with research activities until various Memorandums of Understanding, Terms of Reference, and full financial arrangements are signed off. Joseph and Robinson (2014) comment that the hierarchical structure in Indian science is entrenched through a culture of promotion based on years of service, rather than research excellence or scientific achievements, further reducing any incentive to fast-track innovative research activities and collaborations.

In the PACC, we did not come across such issues of hierarchy. Rather, the institutional conditions at the universities had a major role in shaping the future of the research projects that were initiated during the PACC lifetime. The example of conditions at UNAMBA, which has been continuously affected by strikes and a persistent lack of transparency in regulations, clearly shows how difficult or even impossible it is to make reasonable progress in advancing a research proposal and project under such conditions. At UNSAAC, conditions were also difficult, but did not completely preclude submission, acceptance, and operation of the two projects. Differences in progress can also be attributable to the different ambitions and level of commitment of the respective project leaders.

Publishing. Our experience with scientific publishing in both Peru and India is in line with global trends analysed in Blicharska et al. (2017), who show that more than $85 \%$ of papers on climate change published between 2010 and 2014 were from authors affiliated to research institutions in the North. Figures 2 and 3 show how the bulk of scientific articles activities from the two projects were led by authors in the North (Switzerland in this case). Indian science has almost quadrupled its scholarly output over the past decade to be positioned among the world leaders in terms of numbers of 
published papers, although interestingly, the impact of this work, in terms of citations, remains low (Van Noorden 2015) (Table 1). This lack of scientific impact may partly reflect funding restrictions which limit foreign travel and thereby opportunities (particularly for young scientists) to present their research findings to international audiences (Joseph and Robinson 2014). That only three Indian-led (first author) scientific publications have to date emerged from the joint research activities of IHCAP (Figure 3) suggests more could have been achieved in this regard, keeping in mind that scientific papers were not part of the mandated activities for which the various institutions were contracted. Also, these papers emerged late in the programme, suggesting further locally led publications may have followed under an extended programme. Figure 2 for PACC shows how the peer-reviewed publications led by local Peruvian scientists (albeit a few) only emerged during the second phase of the programme, confirming that extended programme phases might be more useful for building collaborations, capacities and mutual understanding among the project partners. However, while Peruvian researchers led several articles in Peruvian journals, most international publications were first-authored by Swiss researchers.

Figure 2 shows how during the first phase of the project (devoted to capacity building), Peruvian researchers mainly engaged in conference abstracts and only at a later stage were capacities and confidence sufficiently established to enable their own peer-reviewed publications. This is in line with current trends, where more than $75 \%$ of the scientific research in Peru is the result of international collaborations, with Peruvian researchers leading less than $10 \%$ of international research. This might also help explain the relatively high citation rate of the few Peruvian-led publications, that most of these publications are initiated within large projects of international cooperation, and therefore the results are also well publicised and cited by the international community. The overall lack of research ownership and publishing can be attributed to the fact that Peruvian researchers are overburdened with teaching duties during the semester and take additional consultancy assignments outside of semesters to complement the low salaries paid by public universities. Thus, as in India, local researchers require more time and incentives in order to allocate further efforts towards publications. Given the various teaching, administrative, and other burdens that researchers in all countries face, time and resources would need to be prioritised towards scientific publications and outreach, since only through scientific publications and international exposure can the quality control of the undertaken activities be truly assured, bringing benefits and credibility to both the project scientists and the donor organisations.

Data sharing. Data sensitivity, costs, and access difficulties are a well-known hindrance for research collaboration in the Indian Himalayan region, particularly in relation to hydrology and the cryosphere, two key themes under IHCAP. As highlighted by Majumder (2015), the government bodies who are the custodians of hydrological, meteorological and environmental data hold back this information and are reluctant to share it publicly. For non-Indian scientists, there can be difficulties in joining field expeditions on Indian glaciers, and further restrictions on what sensitive data can be shared with international partners. As a consequence of these hurdles, researchers are forced to use lesser-quality data, or as was the case under the glaciological studies in IHCAP, make use of remotely sensed data and other proxy sources. It seems counterproductive and against the spirit of bilateral

Table 1. Number of papers and citation ratio.

\begin{tabular}{llc}
\hline Country & Web of Science documents & Ratio citation/paper \\
\hline USA & $3,943,369$ & 18.06 \\
England & 956,493 & 18.19 \\
Switzerland & 275,758 & 20.82 \\
India & 541,330 & 8.55 \\
Peru & 8902 & 15.16 \\
\hline
\end{tabular}

Notes: Total number of papers and citation rates as of January 2018 on the Web of Sciences for USA, England, Switzerland, India, and Peru. Data include article and review articles only. Data obtained from InCites Essential Science Indicators. ๑ 2017 Clarivate Analytics. 
collaboration that crucial data needed to support understanding of climate change impacts in the Indian Himalayan region is in most parts available, but not accessible to the scientists working on these issues. Data sensitivity was not a problem in Peru, mainly because climate-related data are scarce or non-existent, and hence, efforts were focused on generating baseline data monitoring programmes. Currently, within Peru, issues of data integrity, data ownerships, and management are becoming increasingly prominent in research domains and beyond.

\section{Conclusions and recommendations}

Overall, what emerges from our experience in India and Peru is that the reasons behind the NorthSouth research divide can be different from one country to the other, suggesting that a one-size-fitsall solution will likely not exist. However, there are a number of observations that can have a general validity. An example is the establishment of research collaborations. Given the various points outlined above, fruitful research collaborations can take considerable time to establish and bear fruit. This can be true universally, including between well-established research institutions in the North. Dedicating enough time to strengthening collaborations should be reflected in programme planning, with realistic timescales. Often at the end of a programme or project first phase (typically two to four years), the emphasis moves to out-scaling/up-scaling, but rather more effort and resources should be given towards consolidating existing collaborations and research activities. The ultimate end-goal should be that local scientists are themselves in a position to lead any out-scaling at a later stage.

From our analysis in Peru, it is evident that lack of funding is not necessarily the main reason for the identified gaps (the resources from CANON, if tapped properly, could be very significant), but instead underdeveloped regulatory and institutional frameworks, as well as scientific capacities, come to the fore. It is at these two entry points that any intervention is likely to produce the greatest impact, especially if it recognises the long-term nature of required efforts and investments. In particular for Peru, the improvement of regulatory and institutional frameworks for research as well as strengthening capacity should be a prerequisite for interventions. A new and stronger research culture needs to be established before specific knowledge gaps at the content level can be addressed. In India, the regulatory and institutional framework for research is well established, but the research landscape is broad and diverse. As a result, funding and international collaborations are unequally distributed, promoting an elite culture at the disadvantage of local and less prominent institutions.

As a way forward, bilateral research programmes initiated by national research funds together with donor agencies could be more appropriate than donor-led initiatives, since in this way they would capitalise on the combined mandates of the two institutions, namely the promotion of research excellence on the one side and the development and cooperation needs on the other. Furthermore, any collaboration will yield only if sufficient investment is made in a profound understanding of the respective context. Without these investments (in terms of time and resources), even large investments in a collaboration are at severe risk of being futile.

Contrarily to the common trend of having an increasing on-ground focus of activities in recipient countries, it emerged that in India as well as in Peru the research stays in the donor country (Switzerland) were highly appreciated. These visits provided an opportunity for scientists to see for themselves that the donor and recipient countries are both confronted with many common challenges in the face of climate change, and therefore cemented a realisation that much could be gained from joint experiences. Thus, a recommendation is to dedicate enough funding and time for local scientists to travel and spend dedicated research time in the donor country.

Data sharing is another important aspect to bring forward. We recommend that data-sharing arrangements be put in place before joint research projects are initiated. There is a growing trend from the research funding community to require that data management and sharing plans are detailed at the proposal stage of the projects and put in place ahead of the project start. There is currently a wealth of tools available for data sharing and management, such as Sharepoint, Zotero, 
Resilio, and Citavi. We believe that this should be a prerequisite for future donor investments in the academic context.

\section{Acknowledgements}

This research has been supported by the Global Programme Climate Change and Environment (GPCCE) of the Swiss Agency for Development and Cooperation (SDC).

\section{Disclosure statement}

No potential conflict of interest was reported by the authors.

\section{Notes on contributors}

Veruska Muccione is a Senior Scientist at the Department of Geography, University of Zurich, Switzerland.

Boris Orlowski is a Senior Advisor on Climate Change Adaptation at CARITAS Switzerland. and an affiliated researcher at the Department of Geography, University of Zurich, Switzerland.

Simon Allen is a Research Associate in the Institute for Environmental Sciences, University of Geneva, and Department of Geography, University of Zurich, Switzerland.

Christian Huggel is a Senior Scientist at the Department of Geography, University of Zurich, Switzerland.

Nadine Salzmann is a Senior Scientist and Lecturer at the Department of Geosciences, University of Fribourg, Switzerland.

Nilton Montoya is a Professor in the Agriculture Department and an affiliated researcher at the Research Institute of University and Region (IIUR) of National University of San Antonio Abad of Cusco, Peru.

Surjeet Singh Randhawa is a Senior Scientific Officer with the State Centre on Climate Change under the aegis of the HP Council for Science Technology \& Environment (HIMCOSTE), Shimla, Himachal Pradesh, India.

Markus Stoffel is a Full Professor at the University of Geneva, where he heads the Climate Change Impacts and Risks in the Anthropocene $(\mathrm{C}-\mathrm{CIA})$ team.

\section{References}

Allen, S. K., J. Fiddes, A. Linsbauer, S. S. Randhawa, B. Saklani, and N. Salzmann. 2016. “Permafrost Studies in Kullu District, Himachal Pradesh." Current Science 111 (3): 550-553.

Allen, S. K., A. Linsbauer, S. S. Randhawa, C. Huggel, P. Rana, and A. Kumari. 2016. "Glacial Lake Outburst Flood Risk in Himachal Pradesh, India: An Integrative and Anticipatory Approach Considering Current and Future Threats." Natural Hazards 84 (3): 1741-1763.

Ballesteros Cánovas, J. A., D. Trappmann, M. Shekhar, A. Bhattacharyya, and M. Stoffel. 2017. "Regional Flood-Frequency Reconstruction for Kullu District, Western Indian Himalayas." Journal of Hydrology 546: 140-149.

Blicharska, M., R. J. Smithers, M. Kuchler, G. K. Agrawal, J. M. Gutiérrez, A. Hassanali, S. Huq, et al. 2017. "Steps to Overcome the North-South Divide in Research Relevant to Climate Change Policy and Practice." Nature Climate Change 7 (1): 21 27

Concytec. 2014. "Situación de La Formación de Capital Humano E Investigación En Las Universidades Peruanas: II Censo Nacional Universitario." Lima.

Corbera, E., L. Calvet-Mir, H. Hughes, and M. Paterson. 2015. "Patterns of Authorship in the IPCC Working Group III Report." Nature Climate Change 6 (1): 94-99.

Hewitson, B. 2015. "To Build Capacity, Build Confidence." Nature Geoscience 8 (7): 497-499.

Huggel, C., I. Wallimann-Helmer, D. Stone, and W. Cramer. 2016. "Reconciling Justice and Attribution Research to Advance Climate Policy." Nature Climate Change 6 (10): 901-908.

Hulme, M., and M. Mahony. 2010. "Climate Change: What Do We Know About the IPCC?" Progress in Physical Geography 34 (5): 705-718.

IHCAP. 2016. "Synthesis Report: Climate Vulnerability, Hazards and Risk: An Integrated Pilot Study in Kullu District, Himachal Pradesh." New Dehli: IHCAP.

Joseph, M., and A. Robinson. 2014. "Free Indian Science." Nature 508 (7494): 36-38.

Lavalle, C., and V. Luis De Nicolas. 2017. "Peru and Its New Challenge in Higher Education : Towards a Research University." PLOS ONE 12 (8): 1-12.

Majumder, P. P. 2015. "Priorities for Science in India." Nature 521: 151. 
Muccione, V., S. K. Allen, C. Huggel, and J. Birkmann. 2017. “Differentiating Regions for Adaptation Financing: The Role of Global Vulnerability and Risk Distributions." Wiley Interdisciplinary Reviews: Climate Change 8 (2): 1-8.

Orlowsky, B., N. Andres, N. Salzmann, C. Huggel, C. Jurt, L. Vicuña, M. Rohrer, P. Calanca, R. Neukom, and F. Drenkhan. 2016. "Science in the Context of Climate Change Adaptation: Case Studies from the Peruvian Andes." In Climate Change Adaptation Strategies - An Upstream-Downstream Perspective, edited by N. Salzmann, C. Huggel, S. U. Nussbaumer, and G. Ziervogel, 41-58. Cham: Springer International.

Padma, T. V. 2015. "India: The Fight to Become a Science Superpower." Nature 521 (7551): 144-147.

Pasgaard, M., and N. Strange. 2013. "A Quantitative Analysis of the Causes of the Global Climate Change Research Distribution." Global Environmental Change 23 (6): 1684-1693.

Salzmann, N., C. Huggel, S. U. Nussbaumer, and G. Ziervogel2016. Climate Change Adaptation Strategies - An UpstreamDownstream Perspective. Cham, Switzerland: Springer International.

Salzmann, N., C. Huggel, M. Rohrer, and M. Stoffel. 2014. "Data and Knowledge Gaps in Glacier, Snow and Related Runoff Research - A Climate Change Adaptation Perspective." Journal of Hydrology 518: 225-234.

Van Noorden, R. 2015. "India by the Numbers." Nature 521: 142-143.

Varshney, U. 2015. "Make Science an Attractive Career." Nature 521 (7551): 154-155.

World Bank. 2017. World Development Indicators 2017. Washington, DC: World Bank. Accessed 21 February 2018. https:// openknowledge.worldbank.org/handle/10986/26447. 